Document downloaded from:

http://hdl.handle.net/10251/176437

This paper must be cited as:

Rutkowska, M.; Borcuch, A.; Marzec, A.; Kowalczyk, A.; Samojeden, B.; Moreno, J.; Díaz Morales, UM.... (2020). Influence of iron aggregation on the catalytic performance of desilicated MFI in the DeNO(x) process. Microporous and Mesoporous Materials. 304:1-8. https://doi.org/10.1016/j.micromeso.2018.09.015

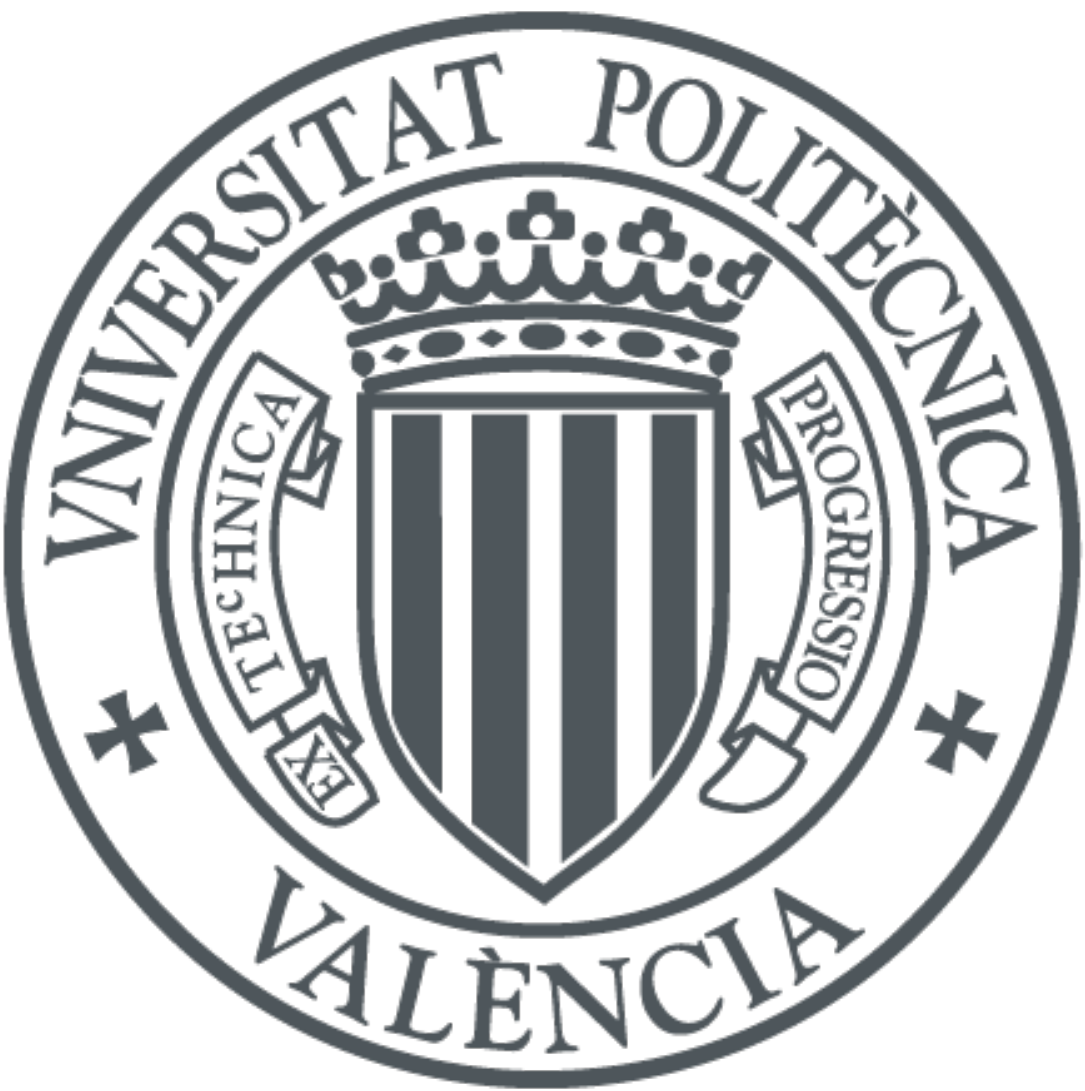

The final publication is available at

https://doi.org/10.1016/j.micromeso.2018.09.015

Copyright Elsevier

Additional Information 


\title{
Influence of iron aggregation on the catalytic performance of desilicated MFI in the DeNO process
}

M. Rutkowska ${ }^{*}$, A. Borcuch ${ }^{1}$, A. Marzec ${ }^{1}$, A. Kowalczyk ${ }^{1}$, B. Samojeden ${ }^{2}$, J.M. Moreno ${ }^{3}$, U.

$$
\text { Díaz }^{3} \text {, L. Chmielarz }{ }^{1}
$$

${ }^{1}$ Jagiellonian University, Faculty of Chemistry, Gronostajowa 2, 30-387 Kraków, Poland

${ }^{2}$ AGH University of Science and Technology, Faculty of Energy and Fuels, Department of Fuels Technology, al. A. Mickiewicza 30, 30-059 Kraków, Poland

${ }^{3}$ Instituto de Tecnología Química, Universitat Politècnica de València - Consejo Superior de Investigaciones Científicas, Avd. de los Naranjos s/n, 46022 Valencia, Spain

*Corresponding author. Tel.: +48 12-686-24-29, e-mail address: rutkowsm@chemia.uj.edu.pl (M. Rutkowska)

Keywords: iron aggregation, oligocations, mesoporous MFI, DeNO ${ }_{\mathrm{x}}$ process

\begin{abstract}
In the presented studies an influence of the iron aggregation in conventional and micromesoporous MFI on their catalytic activity in the $\mathrm{NO}$ reduction with ammonia $\left(\mathrm{DeNO}_{\mathrm{x}}\right.$ process) was studied. Modification of the MFI zeolite properties was done by the desilication in the presence of $\mathrm{NaOH}$ and $\mathrm{TPAOH}$ (tertapropyl ammonium hydroxide). In the next step the samples were modified with iron by ion-exchange with the use of conventional solution of $\mathrm{Fe}$ cations $\left(\mathrm{FeSO}_{4}\right)$ and the solution of iron triple-metallic aggregates (oligocations) $\left(\left[\mathrm{Fe}_{3}(\mathrm{OAc})_{6} \mathrm{O}\left(\mathrm{H}_{2} \mathrm{O}\right)_{3}\right]^{+}\right)$. Both the applied modification techniques (desilication, modification with Fe3 oligocations) increased the catalytic activity of MFI zeolite in the $\mathrm{DeNO}_{\mathrm{x}}$ process.
\end{abstract}


This increased catalytic activity was connected with the changes in the sample porosity, Si/Al ratio, topology as well as aggregation and dispersion of iron species on the catalyst surface (what was investigated by $\mathrm{N}_{2}$-sorption, XRD, AAS, NMR TEM and UV-vis-DRS techniques).

\section{Introduction}

Zeolites belong to the group of microporous crystalline silicates and aluminosilicates, which are widely used in industry, in such fields as - adsorption, separation and catalysis [1-3]. Application of these materials is connected with their unique properties, which are particularly important in catalysis. Uniform porosity, crystallinity, high surface area, hydrothermal stability, acidic and ion-exchange properties make zeolites attractive supports for the catalytic systems. Microporosity present in this group of materials is responsible for the very important feature of zeolites, which is shape selectivity [3]. On the other side, micropores may cause steric limitations connected with a hindered access of molecules (reactants and products) to the catalytically active sites located in narrow pores. The latest scientific papers report, that the generation of mesoporosity inside the structure of zeolites allows to reduce the problems with steric and diffusion restrictions [2-4]. Moreover, the presence of additional mesoporous system increases accessibility of the reactants to active centers, which affects the catalytic performance $[4,5]$.

Generation of mesoporosity within the zeolite structure can be obtained in two ways. First approach is based on direct synthesis of materials with mesopores, while the second family of techniques is associated with the post-synthesis treatment [3-6]. As examples of the most popular techniques used for generation of mesoporosity in zeolites can be listed: desilication [7], dealumination [8], desilication and dealumination [9], mesotemplate-free method [10-12] or modification (delamination and pillarization) of layered zeolites [13]. 
Desilication, due to the economic aspects as well as availability and easiness of use, is a widely practiced method applied for the generation of mesoporosity in the structure of zeolites. This post-synthesis treatment of zeolites consists of their leaching by alkaline solutions. Groen et al. [14] determined the most relevant conditions, such as temperature and time, in the case of the MFI zeolite desilication with $\mathrm{NaOH}$ solution. Such sodium base treatment leads to materials which do not show any significant changes in the basic zeolitic properties such as acidity and the long-range ordered structure [15]. Besides $\mathrm{NaOH}$, as effective agents for desilication of ZSM-5 also $\mathrm{KOH}$ and $\mathrm{LiOH}$ were used [16]. According to Groen et al. [17], the standard treatment of MFI $\left(0.2 \mathrm{M}\right.$ of $\left.\mathrm{NaOH}, 65^{\circ} \mathrm{C}, 30 \mathrm{~min}\right)$ leading to materials with the optimal pore size, can be achieved for zeolites with the $\mathrm{Si} / \mathrm{Al}$ ratio in the range of 25-50. Pérez-Ramírez et al. [18] proposed an alternative approach to obtain zeolites with mesopores, based on the improved microporosity preservation. In this method the silicon extraction is conducted in the presence of the pore-directing agents (PDA), such as tetraalkylammonium cations (e.g. $\mathrm{TBA}^{+}, \mathrm{TPA}^{+}$), which provide protection against excessive silicon dissolution. Desilication of zeolites with this tactic allows to receive materials with the bimodal porous system, where important intrinsic properties are retained.

Introduction of catalytically active components into zeolites can be obtained by various methods, among others the most popular are ion-exchange and impregnation. In the case of conventional microporous zeolites an introduction of metal may result in its deposition in the different forms and aggregation levels on the catalyst surface. In majority of the catalytic reactions the highly aggregated species are inactive or less active than highly dispersed metals species (e.g. monomeric cations). Moreover, they can plague the narrow pores of zeolites decreasing the surface area and hindering the access of reactants to the active sites. In order to overcome this problem various methods of mesoporosity generation in zeolites can be used [19]. More open structure and improved accessibility to the ion-exchange positions enable 
introduction of transition metals in higher amount and in more dispersed forms. This approach resulted in an increase of catalytic activity of zeolites in various reactions, including also catalytic processes important for environmental protection $[6,7,20-22]$.

Iron, due to its high activity, low price and wide availability, was recognized as one of the most interesting transition metals in catalysis. Introduction of Fe into the catalyst's support is connected with co-occurrence of iron species in different forms (mononuclear ions, oligomeric clusters and bulky particles of $\mathrm{Fe}_{2} \mathrm{O}_{3}$ ) [23, 24]. It is very important to adjust and optimize the modification technique (iron source, modification method) in order to obtain the sample with high Fe loading in the form catalytically active in the particular reaction.

According to Macina et al. [25, 26] deposition of metal in the more aggregated, oligomeric form can be achieved by the use of metal acetate complexes. The use of iron oligocations $\left(\left[\mathrm{Fe}_{3}(\mathrm{OAc})_{6} \mathrm{O}\left(\mathrm{H}_{2} \mathrm{O}\right)_{3}\right]^{+}\right)$, obtained according to the method proposed by Maes and Vansant [27], allowed to receive catalysts with iron in the form of oligomeric aggregates [25]. Macina et al. $[25,26]$ found that the catalytic activity of the samples modified with iron oligocations in NO reduction with ammonia $\left(\mathrm{DeNO}_{\mathrm{x}}\right)$ and ammonia oxidation (AMOX), increased in comparison to the samples modified with monomeric iron cations. It is expected that the generation of mesoporosity in zeolites may result in opening of new possibilities of the catalytic supports modification with aggregated metals (oligocations) without the significant blockage of the external surface.

The rapid civilization development caused very high emissions of nitrogen oxides, $\mathrm{NO}_{\mathrm{x}}(\mathrm{NO}$, $\mathrm{NO}_{2}$ ), into the atmosphere, which contributes to the most serious environmental issues. These air pollutants are emitted mainly from fuel combustion processes, which take place in the stationary (e.g. power stations) and mobile sources [28]. Selective catalytic reduction of nitrogen oxides with ammonia $\left(\mathrm{NH}_{3}-\mathrm{SCR}, \mathrm{DeNO}_{\mathrm{x}}\right)$ is the most commonly used method for the elimination of these harmful gases [28, 29]. As active catalysts for this process zeolites, 
noble metals and metal oxides are considered [28, 29]. Zeolites (e.g. Y, BEA, CHA, ZSM-5, FER) modified with transition metals (e.g. $\mathrm{Cu}, \mathrm{Fe}, \mathrm{Co}$ ) are known to be active catalysts in the SCR reactions, which make them very attractive catalysts for $\mathrm{NO}_{\mathrm{x}}$ elimination [22, 30-36]. Moreover, the presence of oligomeric iron oxide species was found to be a crucial factor improving the catalytic performance of the iron-modified samples in the $\mathrm{NH}_{3}$-SCR process $[24,25,35,37]$.

In this study, zeolites with MFI topology, were modified by desilication with two agents: $\mathrm{NaOH}$ and TPAOH. The parent and micro-mesoporous materials were modified with iron solutions, in which metal was present in the form of isolated cations and oligocations. The influence of generated mesoporosity and the form of introduced iron on the catalytic activity in the process of the selective catalytic reduction of $\mathrm{NO}$ with $\mathrm{NH}_{3}$ was investigated.

\section{Experimental methods}

\subsection{Catalysts preparation}

\section{Desilication}

Parent ZSM-5 zeolite with Si/Al = 45 (provided by Clariant Company (Germany), H-form), denoted as MFI, was treated in alkaline solutions of sodium hydroxide (Chempur) and tetrapropylammonium hydroxide (TPAOH, Sigma-Aldrich). Desilication of the MFI material was performed by using of $90 \mathrm{~mL}$ of basic mixture, with the molar ratio $\mathrm{TPA}^{+} / \mathrm{OH}^{-}$of 0.4 and the total concentration of $\mathrm{OH}^{-}$equal to $0.2 \mathrm{M} .3 \mathrm{~g}$ of the powdered parent zeolite was stirred magnetically with the alkaline solution at $500 \mathrm{rpm}$ under reflux at $65^{\circ} \mathrm{C}$ for $4 \mathrm{~h}$. Then, the resulting slurry was cold down in an ice-water mixture, filtrated, washed with distillate water (to obtain $\mathrm{pH}$ of 7 ) and dried at $60^{\circ} \mathrm{C}$ for $24 \mathrm{~h}$.

Afterwards, the material was subjected into triple ion-exchange procedure, in order to its transformation into $\mathrm{H}$-form, with a $0.5 \mathrm{M}$ solution of $\mathrm{NH}_{4} \mathrm{NO}_{3}$ (Sigma-Aldrich) $(80 \mathrm{~mL} / \mathrm{g}$ ) at 
$80^{\circ} \mathrm{C}$ under reflux for $1 \mathrm{~h}$. The resulting solid was filtrated, washed with distillate water, dried at room temperature and calcined at $600^{\circ} \mathrm{C}$ for $6 \mathrm{~h}$. The obtained micro-mesoporous material is denoted as MFI/des.

The parent MFI and MFI/des materials were modified with iron by ion-exchange. For deposition of iron in the form of monomeric cations a solution of $\mathrm{FeSO}_{4} \cdot 7 \mathrm{H}_{2} \mathrm{O}$ (SigmaAldrich) was used, while for deposition of small oligomeric ion oxides aggregates (oligocations) the solution of $\left[\mathrm{Fe}_{3}\left(\mathrm{OCOCH}_{3}\right)_{7} \cdot \mathrm{OH} \cdot 2 \mathrm{H}_{2} \mathrm{O}\right] \mathrm{NO}_{3}$ ), prepared according to the procedures presented in $[25,26]$, was applied.

\section{Ion-exchange method}

The parent MFI and MFI/des materials, previously dried overnight at $110^{\circ} \mathrm{C}$, were modified with iron solution of $\mathrm{FeSO}_{4} \cdot 7 \mathrm{H}_{2} \mathrm{O}(250 \mathrm{~mL} / 3 \mathrm{~g})$ by stirring at $500 \mathrm{rpm}$ under reflux at $85^{\circ} \mathrm{C}$ for $6 \mathrm{~h}$. The solution concentration was calculated for each sample basing on its theoretical ion-exchange capacity (with molar excess $\mu=0.4$ ). During stirring the slurry was kept under Ar atmosphere in order to avoid iron oxidation. After ion-exchange, the resulting samples were quenched in an ice-bath, centrifuged (3500 rpm, $15 \mathrm{~min}$ ), washed with distillated water, dried at $60^{\circ} \mathrm{C}$ overnight and finally calcined at $600^{\circ} \mathrm{C}$ for $6 \mathrm{~h}$.

The samples obtained as a result of modification with $\mathrm{FeSO}_{4} \cdot 7 \mathrm{H}_{2} \mathrm{O}$ solution are denoted as $\mathrm{Fe}(\mathrm{IE}) \mathrm{MFI}$ and $\mathrm{Fe}(\mathrm{IE}) \mathrm{MFI} / \mathrm{des}$, for the parent and desilicated materials respectively.

In the case of iron oligocations $\left(\left[\mathrm{Fe}_{3}\left(\mathrm{OCOCH}_{3}\right)_{7} \cdot \mathrm{OH} \cdot 2 \mathrm{H}_{2} \mathrm{O}\right] \mathrm{NO}_{3}\right)$ the same ion-exchange procedure was used. The sample codes of the final materials are Fe3(IE)MFI and Fe3(IE)MFI/des, for the parent and desilicated materials respectively.

All the sample codes and the parameters of their modification procedures are presented in Tab. 1. 
Tab. 1. Sample codes and description of their modification procedures

\begin{tabular}{|l|l|l|}
\hline Sample code & Desilication & Fe source \\
\hline HMFI & ----- & ----- \\
\hline HMFI/des & $65^{\circ} \mathrm{C}$ for $4 \mathrm{~h}$ & ----- \\
\hline FeMFI & ----- & $\mathrm{FeSO}_{4} \cdot 7 \mathrm{H}_{2} \mathrm{O}$ \\
\hline FeMFI/des & $65^{\circ} \mathrm{C}$ for $4 \mathrm{~h}$ & $\mathrm{FeSO}_{4} \cdot 7 \mathrm{H}_{2} \mathrm{O}$ \\
\hline Fe3MFI & ----- & {$\left[\mathrm{Fe}_{3}\left(\mathrm{OCOCH}_{3}\right)_{7} \cdot \mathrm{OH} \cdot 2 \mathrm{H}_{2} \mathrm{O}\right] \mathrm{NO}_{3}$} \\
\hline Fe3MFI/des & $65^{\circ} \mathrm{C}$ for $4 \mathrm{~h}$ & {$\left[\mathrm{Fe}_{3}\left(\mathrm{OCOCH}_{3}\right)_{7} \cdot \mathrm{OH} \cdot 2 \mathrm{H}_{2} \mathrm{O}\right] \mathrm{NO}_{3}$} \\
\hline
\end{tabular}

\subsection{Catalysts characterization}

Textural properties of the samples were determined by $\mathrm{N}_{2}$ sorption at $-196^{\circ} \mathrm{C}$ using a 3 Flex v1.00 (Micromeritics) automated gas adsorption system. Prior to the analysis, the samples were outgassed under vacuum at $350^{\circ} \mathrm{C}$ for $24 \mathrm{~h}$. The specific surface area of the samples was determined using BET (Braunauer-Emmett-Teller) model according to the recommendations of Rouquerol at al. [38]. The micropore volume and external surface area were calculated using the Harkins and Jura model ( $\mathrm{t}$-plot analysis, thickness range 0.55-0.85 nm). Mesopore volume was calculated from desorption branch using BJH model (Kruk-Jaroniec-Sayari empirical procedure) in the range of $1.7-30.0 \mathrm{~nm}$.

The X-ray diffraction (XRD) patterns of the samples were recorded using a Bruker D2 Phaser instrument. The measurements were performed in the 2 theta range of $5-50^{\circ}$ with a step of $0.02^{\circ}$

Transmission electron microscopy (TEM) micrographs were collected by a JEOL JEM2100F electron microscope operating at $200 \mathrm{keV}$.

The transition metals content was analyzed by means of atomic absorption spectroscopy (Spectra A A10 Plus, Varian).

${ }^{27} \mathrm{Al}$ NMR and ${ }^{29} \mathrm{Si}$ NMR spectra were recorded with a Bruker AV400 spectrometer. Details The UV-vis-DR spectra of the samples modified with iron were recorded using an Evolution 600 (Thermo) spectrophotometer in the range of $200-900 \mathrm{~nm}$ with a resolution of $2 \mathrm{~nm}$. 


\subsection{Catalytic tests}

The obtained micro-mesoporous materials and reference conventional zeolites, modified with iron, were tested as catalysts of selective catalytic reduction of $\mathrm{NO}$ with ammonia $\left(\mathrm{NH}_{3}-\mathrm{SCR}\right.$, DeNO ${ }_{x}$ ). Catalytic studies were performed in a fixed-bed quartz microreactor, at atmospheric pressure, in the temperature range of $100-600^{\circ} \mathrm{C}$. For each test $0.1 \mathrm{~g}$ of catalyst, with a particle size between 0.160 and $0.315 \mathrm{~mm}$, was outgassed in a flow of pure $\mathrm{He}(20 \mathrm{~mL} / \mathrm{min})$ at $600^{\circ} \mathrm{C}$ for $1 \mathrm{~h}$. The reaction mixture consisted of: $[\mathrm{NO}]=0.25 \mathrm{vol} . \%,\left[\mathrm{NH}_{3}\right]=0.25 \mathrm{vol} \%$, $\left[\mathrm{O}_{2}\right]=2.5 \mathrm{vol} \%$ (total flow rate of the reaction mixture was $40 \mathrm{~mL} / \mathrm{min}$ ). The reactant concentrations were continuously measured using a quadrupole mass spectrometer (Prevac) connected directly to the reactor outlet.

\section{Results and discussion}

\subsection{Parent and micro-mesoporous MFI}

The changes in the porous structure and crystallinity, which occurred after modification of HMFI by desilication were investigated by $\mathrm{N}_{2}$-sorption and powder X-ray diffraction (XRD) (Fig. 1). Base treatment of HMFI resulted in the change of the dinitrogen sorption isotherm shape from the type Ia to IVa (Fig.1A). The former type is characteristic of microporous materials, while IVa of mesoporous materials (with mesopore diameter > 4nm) [39]. The shape of the hysteresis loop evidences creation of mesopores in a wide range of pore sizes. The changes in the isotherm shape proved the successful generation of mesoporosity in the sample.

Generation of mesoporosity in HMFI was connected with the loss in crystallinity (Fig. 1B). In the case of $\mathrm{HMFI} / \mathrm{des}$ the reflections characteristic of the MFI structure [7, 40, 41] are much less intensive than for unmodified HMFI. However, it is important to notice that the zeolitic character of the MFI topology was still preserved after base treatment. 

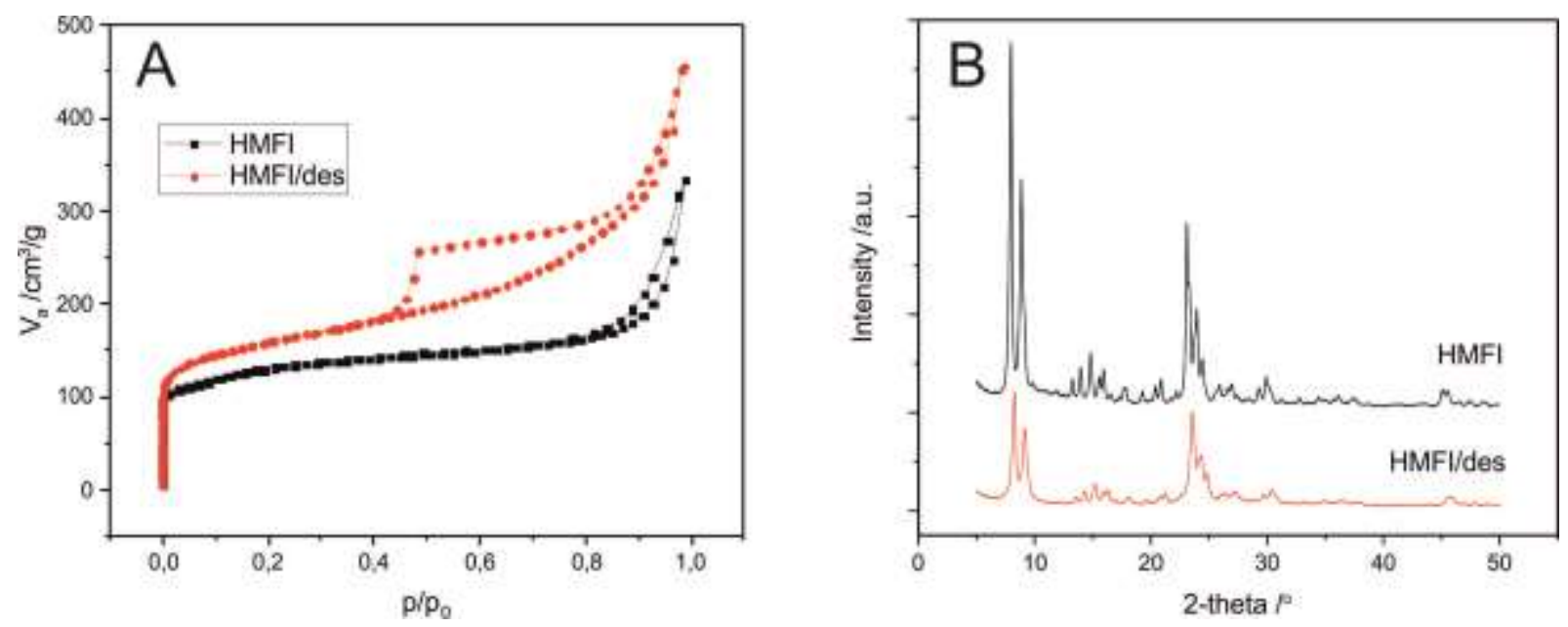

Fig. 1. Nitrogen adsorption-desorption isotherms (A) and PXRD patterns (B) of the parent

HMFI and desilicated HMFI/des samples

The changes in the nitrogen sorption isotherms and X-ray diffractograms are also reflected in the textural parameters of the samples (Tab. 2). After desilication BET and external surface areas as well as the volume of mesopores significantly increased, which occurred in a favour of the microporosity loss. The volume of micropores decreased by about $25 \%$, while the external surface area increased almost four times. Thus, it can be concluded that the applied conditions of desilication enabled significant development of the sample surface parameters, increasing the access to the active sites, with a relatively small loss in microporosity.

Tab. 2. Textural properties of the samples determined from $\mathrm{N}_{2}$-sorption measurements

\begin{tabular}{|l|l|l|l|l|}
\hline Sample code & $\begin{array}{l}\mathrm{S}_{\mathrm{BET}} \\
/ \mathrm{m}^{2} / \mathrm{g}\end{array}$ & $\begin{array}{l}\mathrm{S}_{\mathrm{EXT}} \\
/ \mathrm{m}^{2} / \mathrm{g}\end{array}$ & $\begin{array}{l}\mathrm{V}_{\mathrm{MIC}} \\
/ \mathrm{cm}^{3} / \mathrm{g}\end{array}$ & $\begin{array}{l}\mathrm{V}_{\mathrm{MES}} \\
/ \mathrm{cm}^{3} / \mathrm{g}\end{array}$ \\
\hline HMFI & 462 & 72 & 0,178 & 0,233 \\
\hline HMFI/des & 571 & 266 & 0,130 & 0,491 \\
\hline FeMFI & 467 & 71 & 0,176 & 0,210 \\
\hline FeMFI/des & 548 & 274 & 0,113 & 0,485 \\
\hline Fe3MFI & 449 & 78 & 0,167 & 0,247 \\
\hline Fe3MFI/des & 520 & 276 & 0,102 & 0,509 \\
\hline
\end{tabular}


The changes occurring in the sample morphology after desilication were analysed by transmission electron microscopy (TEM) studies. Fig. 2 presents the micrographs of conventional HMFI zeolite (Fig. 2A) and desilicated sample, HMFI/des (Fig. 2B). After the base treatment well visible cavities were created. Apart the randomness of the desilication process, the generated 'meso-holes' are rather uniformly distributed. The pore sizes of the cavities are not uniform, however in general they are smaller than $10 \mathrm{~nm}$, what is consistent with the results of nitrogen sorption measurements.
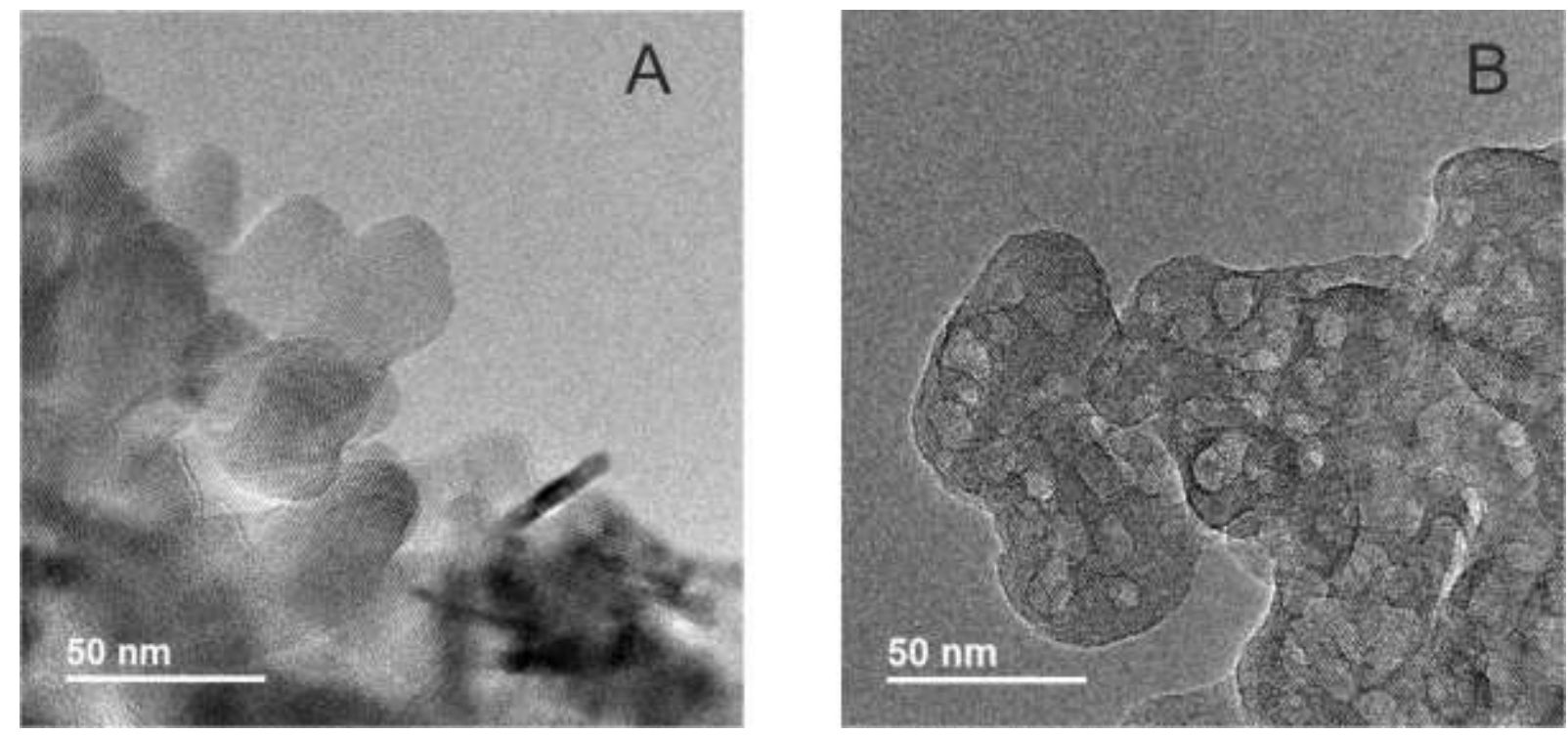

Fig. 2. TEM micrographs of HMFI zeolite before (A) and after (B) desilication

The Si/Al ratio in the samples changed after desilication. Tab. 3 presents the content of Si and $\mathrm{Al}$ in the samples as well as the Si/Al ratio in the HMFI and HMFI/des measured by atomic absorption spectroscopy (AAS). The Si/Al ratio in HMFI, equal to 43, decreased after desilication to 31. An increase in aluminium content can be explained by the removal of silicon during desilication process, what caused a relative growth of $\mathrm{Al}$ content in the sample. Fig. 3. shows the ${ }^{29} \mathrm{Si} \mathrm{NMR}$ (Fig. 3A) and ${ }^{27} \mathrm{Al}$ MAS NMR (Fig. 3B) spectra recorded for the parent and desilicated HMFI samples. The ${ }^{29} \mathrm{Si} \mathrm{NMR}$ spectra of the parent sample exhibited bands centred at $-113.3 \mathrm{ppm}$ and $-106.4 \mathrm{ppm}$, while for the desilicated zeolite signals at 112.6 ppm and $-106.4 \mathrm{ppm}$ are observed. First of the signals, at about 112-113 ppm, possibly 
correspond to $\mathrm{Si}(4 \mathrm{Si})$ species, while the presence of $\mathrm{Si}(3 \mathrm{Si}, 1 \mathrm{Al})$ sites may indicate the chemical shift at $-106.4 \mathrm{ppm}[42,43]$. In the case of the desilicated sample $\mathrm{Q}^{4}$ signal slightly decreased after alkaline treatment in comparison to the parent material, what proves subtraction of the silicon atoms from the zeolitic structure. The intensity of the signal for $\mathrm{Si}(3 \mathrm{Si}, 1 \mathrm{Al})$ species reminded almost unchanged during the applied desilication procedure. It may indicate that, $\mathrm{Si}$ atoms are easier removed by alkaline solution from $\mathrm{Q}^{3}$ coordination in comparison to silicon surrounded by $\mathrm{Si}(4 \mathrm{Si})$ sites $[42,43]$. In the ${ }^{27} \mathrm{Al}$ MAS NMR spectra for both the samples one intensive signal centred at about 53 ppm was observed. This signal can be assigned to tetrahedrally coordinated aluminum [44]. The signal connected with the occurrence of octahedral $\mathrm{Al}(0 \mathrm{ppm})$ is not observed in the case of the studied samples [42, 44]. The lack of the extra-framework aluminum and increase in the intensity of the peak related to the tetrahedral $\mathrm{Al}$ (growth of relative $\mathrm{Al}$ content, Tab. 3) proves, that during the applied desilication procedure framework aluminum reminded in the zeolitic structure [42].

Tab. 3. Silicon, aluminum and iron content and the Si/Al ratio in the samples (determined by AAS analysis)

\begin{tabular}{|l|l|l|l|l|}
\hline Sample code & $\begin{array}{l}\mathrm{Si} \\
\text { /wt.\% }\end{array}$ & $\begin{array}{l}\mathrm{Al} \\
\text { /wt.\% }\end{array}$ & Si/Al & $\begin{array}{l}\mathrm{Fe} \\
\text { /wt.\% }\end{array}$ \\
\hline HMFI & 45.8 & 1.1 & 43 & - \\
\hline HMFI/des & 44.4 & 1.5 & 31 & - \\
\hline FeMFI & 44.3 & 1.1 & 43 & 0.6 \\
\hline FeMFI/des & 42.6 & 1.5 & 30 & 0.4 \\
\hline Fe3MFI & 41.1 & 1.2 & 35 & 6.2 \\
\hline Fe3MFI/des & 42.1 & 1.3 & 33 & 5.1 \\
\hline
\end{tabular}



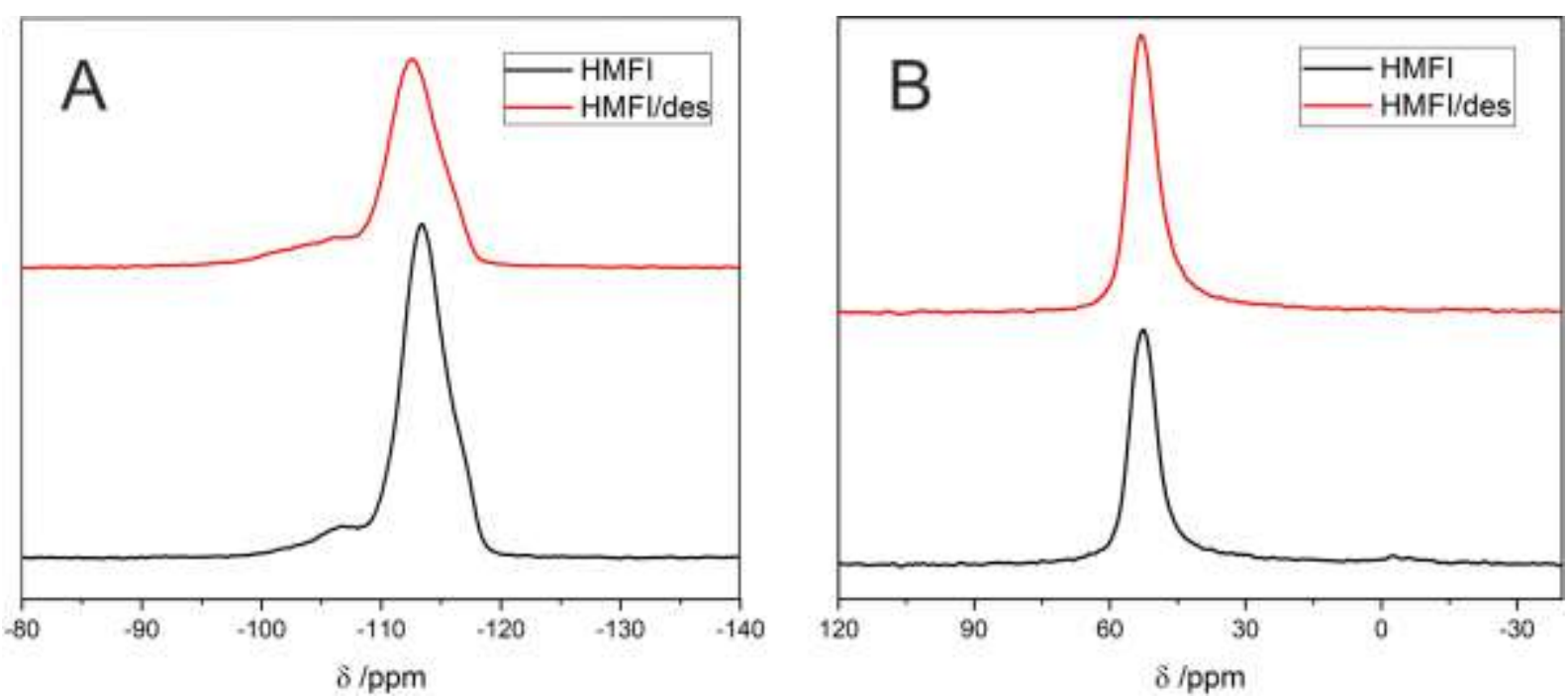

Fig. 3. ${ }^{29} \mathrm{Si} \mathrm{NMR}$ (A) ${ }^{27} \mathrm{Al}$ NMR (B) profiles for parent and desilicated HMFI zeolites

\subsection{Iron modified samples}

HMFI and HMFI/des were modified with iron with the use of $\mathrm{FeSO}_{4}$ and iron $\mathrm{Fe} 3$ oligocations. Textural parameters of the samples after modification with iron (Tab. 2) did not change significantly. In general all textural parameters slightly decreased, however in the case of the samples modified with iron oligocations the external surface area and volume of mesopores slightly increased. This phenomenon could be connected with deposition of small iron aggregates on the surface what could develop both the external surface area and volume of mesopores. Nitrogen sorption isotherms did not change significantly after modification of the samples with iron (results not shown).

The XRD powder patterns of the samples modified with iron are presented in Fig. 4. The reflections characteristics of the MFI structure were obtained for all the samples. It indicates that the zeolitic character of the catalysts was maintained after these modifications. The intensity of the reflections of FeMFI/des and Fe3MFI/des is lower in comparison to the HMFI samples modified with iron (same as in Fig. 1B) what is connected with the desilication 
process. Moreover, no reflections connected with the presence of $\mathrm{Fe}_{2} \mathrm{O}_{3}$ crystallites were found, which confirms deposition of in the form of highly dispersed species [37, 40, 45].

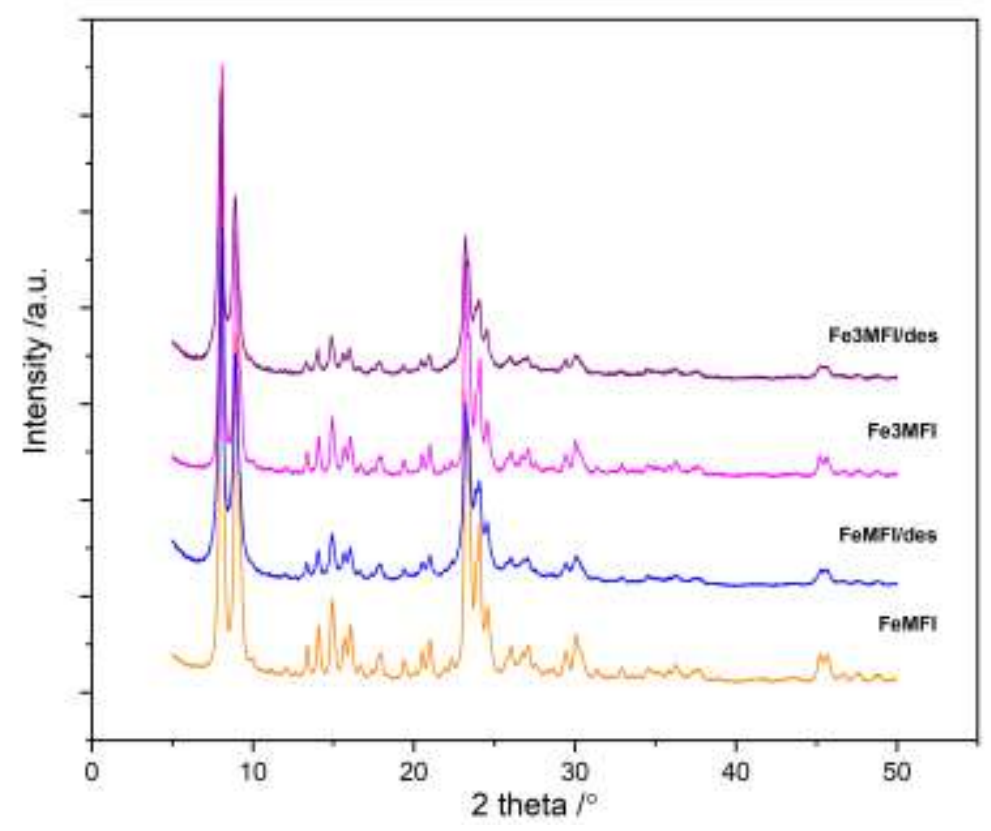

Fig. 4. PXRD patterns of the HMFI and HMFI/des samples modified with iron

The amount of introduced iron (Tab. 3) strongly depends on the Fe source used $\left(\mathrm{FeSO}_{4}\right.$ or $\mathrm{Fe} 3$ oligocations). Despite the same modification procedure (ion-exchange) with the use of oligocations introduction above 5 wt.\% of iron was possible, while in the case of $\mathrm{FeSO}_{4}$ solution the content of deposited iron was below $1 \mathrm{wt} . \%$.

The form of the introduced into the samples iron (coordination and aggregation) was analysed by the UV-vis-DR spectroscopy. The spectra recorded for the materials modified with $\mathrm{FeSO}_{4}$ and $\mathrm{Fe} 3$ oligocations are presented in Fig. $5 \mathrm{~A}$ and $\mathrm{B}$, respectively. The difference in iron content, depending on the used Fe source (measured by AAS), is also visible in the intensity of the UV-vis absorption bands (spectra obtained for the samples modified with $\mathrm{Fe} 3$ oligocations are significantly more intensive). Three main regions can be distinguished in the iron absorption spectrum. Absorption band below $300 \mathrm{~nm}$ is connected with the presence of monomeric $\mathrm{Fe}^{3+}$ cations, while the band located in the range of $300-400 \mathrm{~nm}$ is attributed to small oligomeric $\mathrm{Fe}_{\mathrm{x}} \mathrm{O}_{\mathrm{y}}$ species. The band above $400 \mathrm{~nm}$ could be assigned to the presence of 
more aggregated iron oxide species [46, 47]. The use of $\mathrm{FeSO}_{4}$ solution for the samples modification resulted in introduction of iron mainly in the form of isolated cations into the desilicated (FeMFI/des) sample, while in the case of FeMFI more aggregated iron species were created. This difference could be connected with the more open structure and better accessibility of reactants to acid sites after desilication, which enables better distribution of iron on the surface. Modification of the surface with Fe3 oligocations in both cases (Fe3MFI and $\mathrm{Fe} 3 \mathrm{MFI} / \mathrm{des})$ resulted in various forms of iron - oligomeric species but also monomeric cations and bulky metal oxides forms. The intensity of the bands is not proportional to the content of the particular iron forms in the samples, so it can not be judged which form is prevailing.
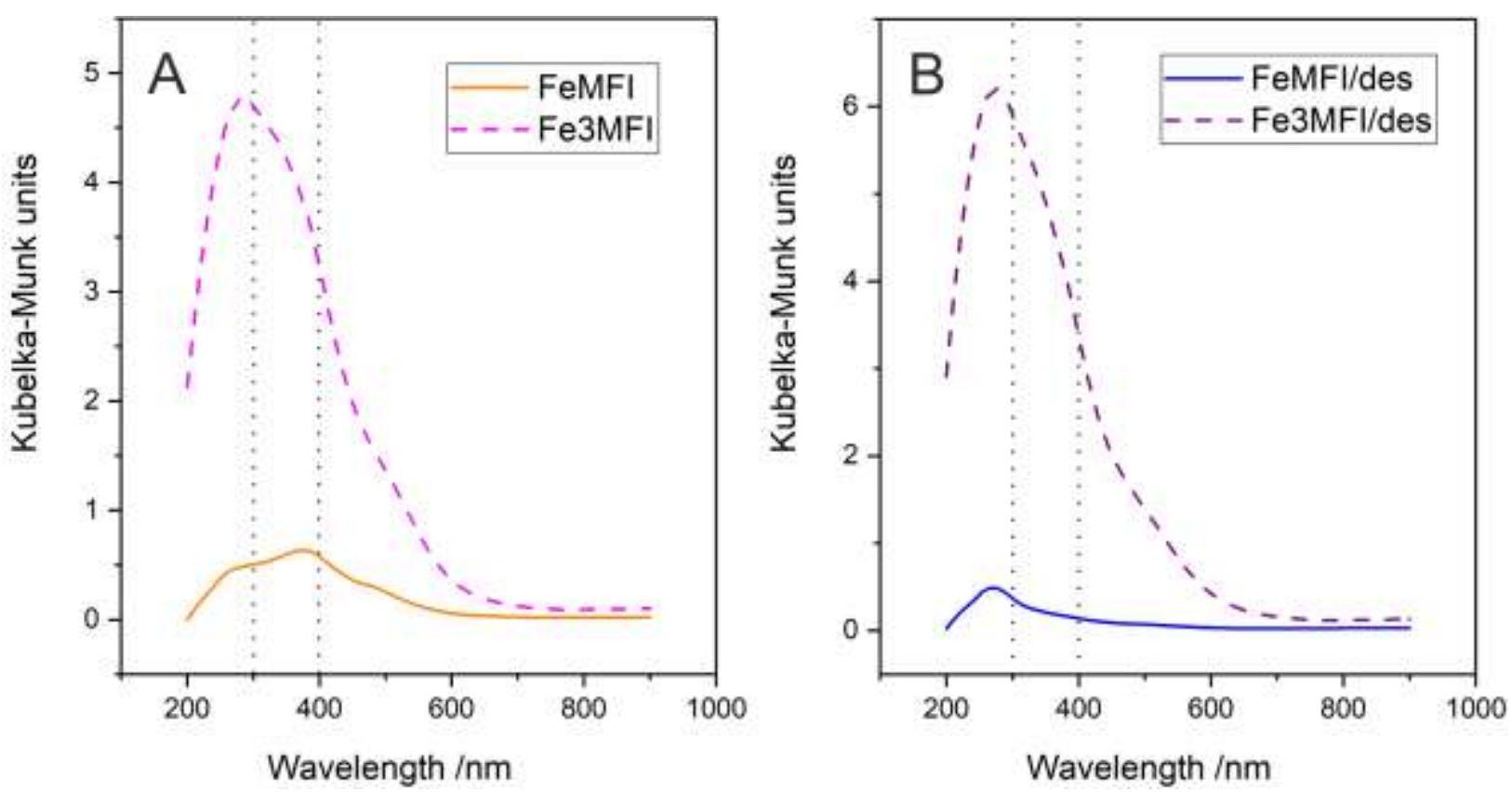

Fig. 5. UV-vis-DR spectra of the parent (A) and desilicated (B) samples modified with $\mathrm{FeSO}_{4}$ and $\mathrm{Fe} 3$ oligocations

Fig. 6 and 7 show the transmission electron microscopy (TEM) micrographs recorded for parent MFI and desilicated MFI/des zeolites modified with iron, respectively. In the case of 
FeMFI (Fig. 6A) only the arrangement of micropores in the zeolite crystals is visible, without any agglomerates of iron. Examination of the sample by EDX reveals the uniform distribution of $\mathrm{Fe}$ on the sample surface (results not shown). On the other side distinct bulky iron aggregates of the sizes of about 3-7 nm are visible on the surface of Fe3MFI (Fig. 6B) (confirmed by EDX, results not shown). The surface of the desilicated samples modified with iron is much more inhomogeneous through the presence of meso-cavities (Fig. 7). Similar as in case of conventional MFI zeolite uniform iron distribution was observed in the case of modification with $\mathrm{FeSO}_{4}(\mathrm{FeMFI} / \mathrm{des})$ and regular iron species domains by the modification with $\mathrm{Fe} 3$ oligocations (Fe3MFI/des).
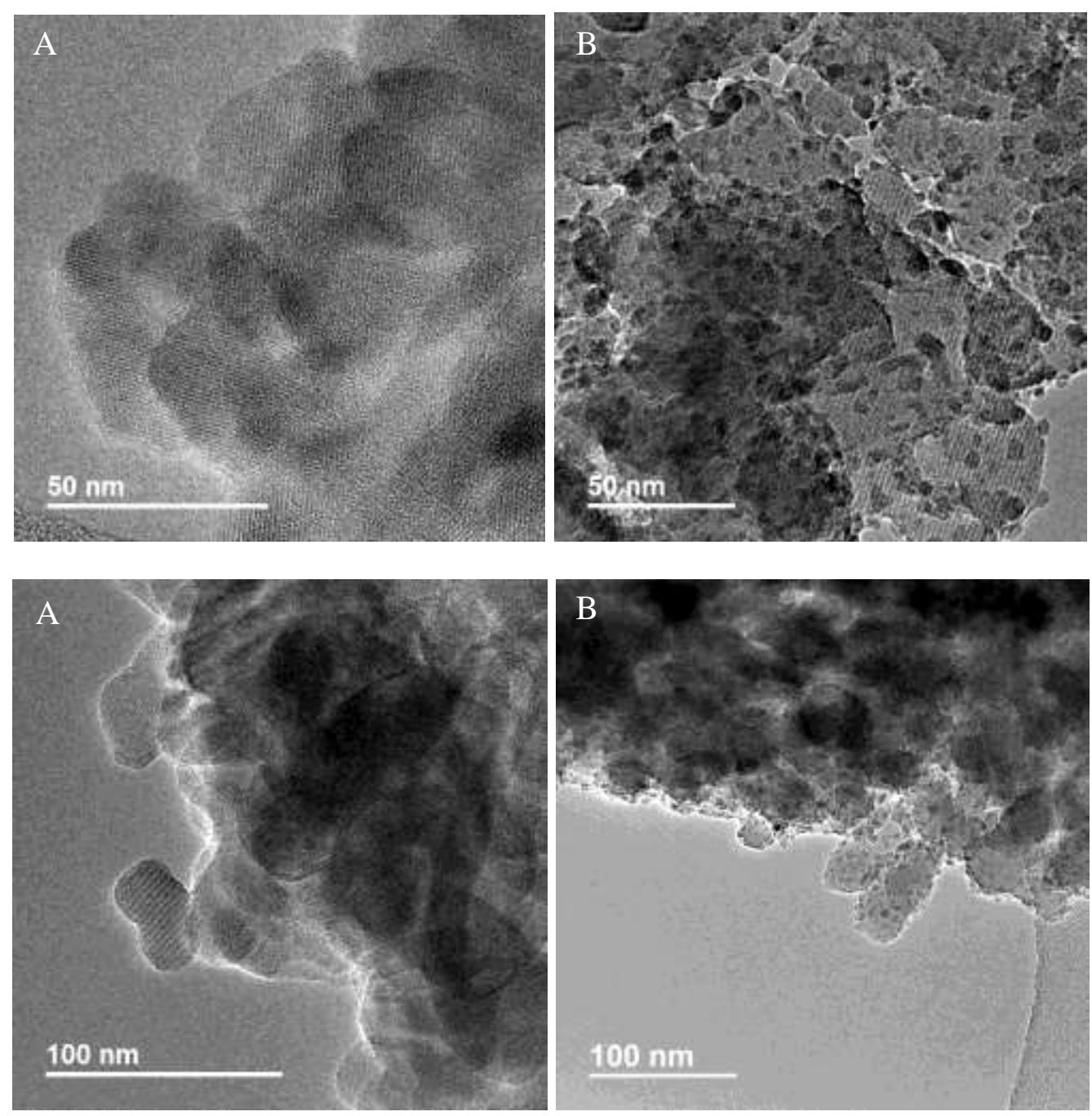

Fig. 6. TEM micrographs of parent MFI zeolite modified with $\mathrm{FeSO}_{4}(\mathrm{FeMFI})(\mathrm{A})$ and $\mathrm{Fe} 3$ oligocations (Fe3MFI) (B) at two magnifications 

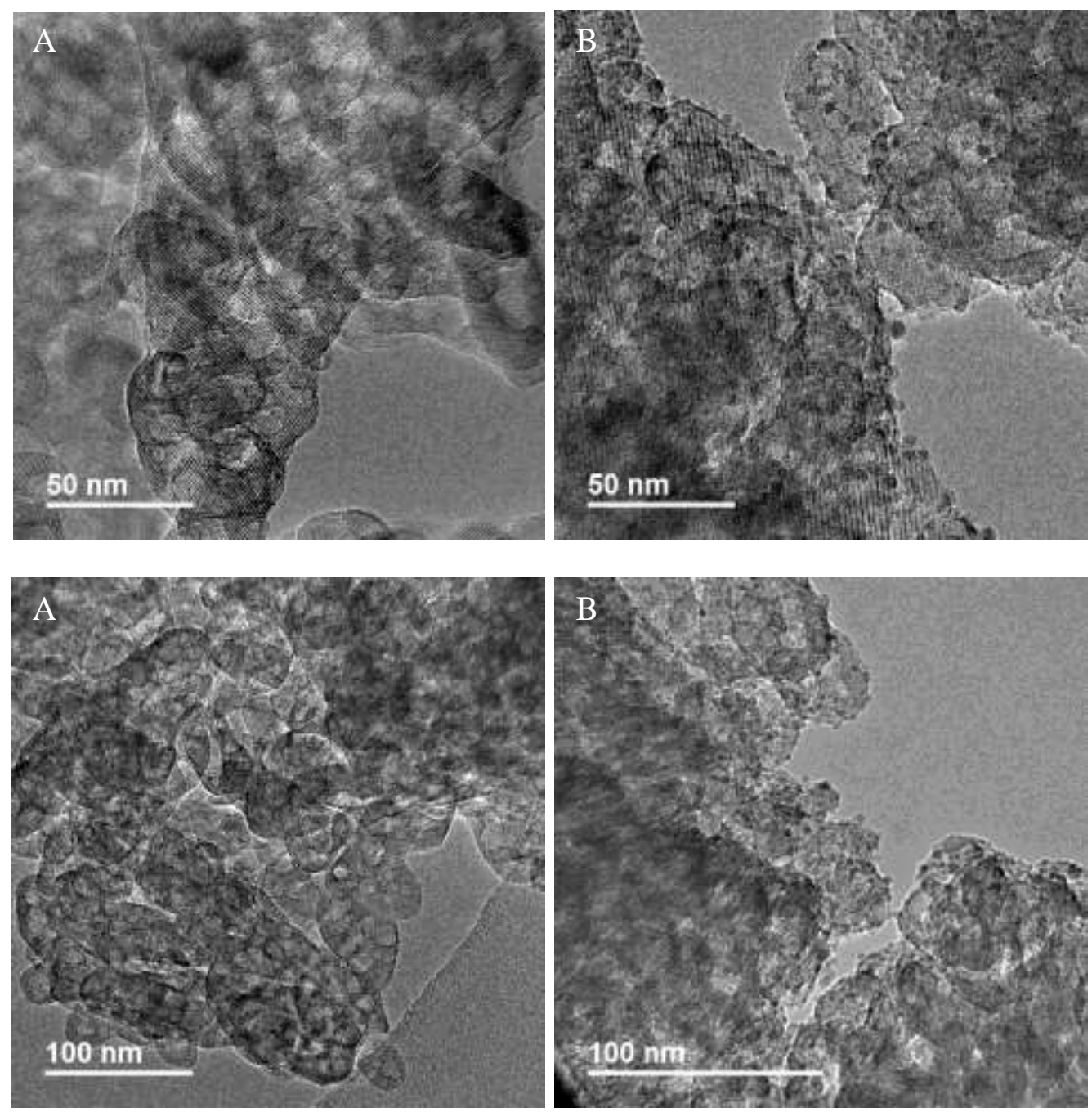

Fig. 7. TEM micrographs of desilicated MFI zeolite modified with iron cations $\mathrm{FeSO}_{4}$

(FeMFI/des) (A) and Fe3 oligocations (Fe3MFI/des) (B) at two magnifications

\subsection{Catalytic study}

The catalytic activity of the obtained samples, modified with iron, in the catalytic reduction of NO with ammonia is presented in Fig. 8. All the samples were active in the studied catalytic reaction, however both applied modifications, desilication and modification with $\mathrm{Fe} 3$ oligocations, increased their efficiency. For the most active samples, Fe3MFI and $\mathrm{Fe} 3 \mathrm{MFI} / \mathrm{des}, 100 \%$ of $\mathrm{NO}$ conversion at about $300^{\circ} \mathrm{C}$ was reached. At high temperatures (above $500^{\circ} \mathrm{C}$ ) the NO conversion over all the samples slightly decreased, what is connected 
with the competitive reaction of ammonia oxidation. It is worth to mention that the selectivity of the process to dinitrogen was very high in the case of all the samples (above 95\%).

Compering the catalytic activity of FeMFI and FeMFI/des, higher catalytic activity showed the desilicated sample. Increased relative concentration of negatively charged Al sites in the desilicated sample could have the positive effect, through the enhancement of ammonia reservoir on the catalyst surface (used for NO reduction). Higher catalytic activity of the samples modified with $\mathrm{Fe} 3$ oligocations can be strictly connected with the higher iron content in the samples. The use of Fe oligocations solution for ion-exchange resulted in introduction of significantly higher content of active phase in the form of the uniformly distributed small bulky species. It is worth to mention that application of other methods, which enable introduction of higher metal contents, such as impregnation may lead to the blocking of the porous zeolitic system by the highly agglomerated metal oxide species.

Same as in the case of the samples modified with $\mathrm{FeSO}_{4}$ higher activity of the mesoporous Fe3MFI/des sample at low temperatures can be connected with the higher relative aluminum content.

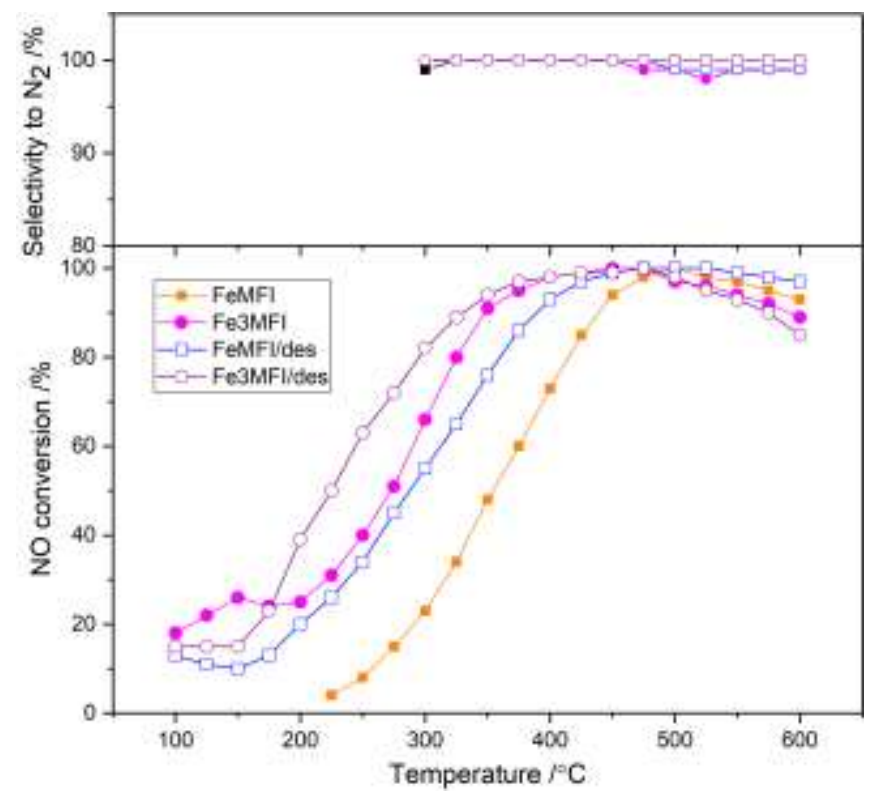

Fig. 8. Temperature dependence of $\mathrm{NO}$ conversion and $\mathrm{N}_{2}$ selectivity in $\mathrm{SCR}$ of $\mathrm{NO}$ with $\mathrm{NH}_{3}$ for parent and desilicated MFI modified with $\mathrm{FeSO}_{4}$ and $\mathrm{Fe} 3$ oligocations 


\section{Conclusions}

The applied modification of HMFI zeolite with the base solution of $\mathrm{NaOH}$ and TPAOH resulted in generation of significant mesoporosity with a relative small decrease in the sample microporosity and crystallinity. The generated mesoporosity was in the form of cavities (with diameter below $10 \mathrm{~nm}$ ), uniformly distributed on the sample surface. Moreover, the HMFI/des sample was characterised by the lower $\mathrm{Si} / \mathrm{Al}$ ratio (higher relative Al content) caused by $\mathrm{Si}$ removal. Modification of the samples with $\mathrm{Fe} 3$ triple-metalic oligocations enabled introduction of significantly higher iron content (in comparison to ion-exchange with $\mathrm{FeSO}_{4}$ ) in the form of uniformly dispersed on the surface small bulky species (not detected by XRD) with the diameter in the range of about 3-7 $\mathrm{nm}$. The highest catalytic activity in the NO reduction with ammonia showed the Fe3MFI/des and Fe3MFI samples (modified with $\mathrm{Fe} 3$ oligocations and by desilication), which make the applied modification techniques very promising for various catalytic reactions.

\section{Acknowledgements}

This work was carried out in the frame of project No. 0670/IP3/2016/74 from the Polish Ministry of Science and Higher Education in the years 2016-2019 and in the frame of project No. 2012/05/B/ST5/00269 from the National Science Centre (Poland).

U. D. acknowledges to the Spanish Government by the funding (MAT2017-82288-C2-1-P).

\section{References}

[1] A. Corma, Chem. Rev., 95 (1995) 559-614.

[2] C.E.A. Kirchhock, S.P.B. Kremer, J. Vermant, G. Van Tendeloo, P.A. Jacobs, J.A. Martens, Chem. Eur. J., 11 (2005) 4306-4313.

[3] D.P. Serrano, J.M. Escola, P. Pizarro, Chem. Soc. Rev., 42 (2013) 4004-4035. 
[4] J. Čejka, S. Mintova, Catal. Rev., 49 (2007) 457-509.

[5] J.C. Groen, J.A. Moulijn, J. Pérez-Ramírez, J. Mater. Chem. 16 (2006) 2121-2131.

[6] A.L. Kustov, T.W. Hansen, M. Kustova, C.H. Christensen, Appl. Catal. B, 76 (2007) 311319.

[7] M. Rutkowska, I. Pacia, S. Basąg, A. Kowalczyk, Z. Piwowarska, M. Duda, K.A. Tarach, K. Góra-Marek, M. Michalik, U. Díaz, L. Chmielarz, Micropor. Mesopor. Mat., 246 (2017) 193-206.

[8] H.K. Beyer, in Molecular Sieves Science and Technology-Post-Synthesis Modification, ed. H.G. Karge and J. Weitkamp, Springer, Berlin, Vol. 3, Chapter 3 (2002) 203-255.

[9] M. Rutkowska, M. Duda, A. Kowalczyk, L. Chmielarz, C.R. Chimie, 20 (2017) 850-859.

[10] M. Rutkowska, L. Chmielarz, D. Macina, Z. Piwowarska, B. Dudek, A. Adamski, S. Witkowski, Z. Sojka, L. Obalova, C.J. Van Oers, P. Cool, Appl. Catal. B, 146 (2014) 112122.

[11] M. Rutkowska, Z. Piwowarska, E. Micek, L. Chmielarz, Micropor. Mesopor. Mat., 209 (2015) 54-65.

[12] M. Rutkowska, D. Macina, Z. Piwowarska, M. Gajewska, U. Díaz, L. Chmielarz, Catal. Sci. Technol., 6 (2016) 4849-4862.

[13] M. Rutkowska, U. Díaz, A.E. Palomares, L. Chmielarz, Appl. Catal. B, 168 (2015) 531539.

[14] J.C. Groen, L.A.A. Peffer, J.A. Moulijn, J. Pérez-Ramírez, Colloids Surf. A, 241 (2004) 53-58.

[15] J.C. Groen, L.A.A. Peffer, J.A. Moulijn, J. Pérez-Ramírez, Micropor. Mesopor. Mat., 69 (2004) 29-34.

[16] J.C. Groen, J.A. Moulijn, J. Pérez-Ramírez, Ind. Eng. Chem. Res., 46 (2007) 4193-4201. 
[17] J.C. Groen, J.C. Jansen, J.A. Moulijn, J. Pérez-Ramírez, J. Phys. Chem. B, 108 (2004) $13062-13065$.

[18] J. Pérez-Ramírez, D. Verboekend, A. Bonilla, S. Abelló, Adv. Funct. Mater., 19 (2009) 3972-3979.

[19] D. Farrusseng, A. Tuel, in Encapsulated Catalysts, ed. Samahe Sadjadi, Elsevier, Chapter 11 (2017) 335-386.

[20] M. Rutkowska, L. Chmielarz, in Advances in Materials Science Research, ed. M.C. Wythers, Nova Science Publishers, Inc, New York, Vol. 22, Chapter 6 (2016) 137-156.

[21] J. Ma, D. Weng, X. Wu, Z. Si, Z. Wu, Prog. Nat. Sci.: Mat. Int., 23 (5) (2013) 493-500.

[22] K. Góra-Marek, K. Brylewska, K.A. Tarach, M. Rutkowska, M. Jabłońska, M. Choi, L. Chmielarz, Appl. Catal. B, 179 (2015) 589-598.

[23] M.S. Kumar, M. Schwidder, M. Grünert, A. Brückner, J. Catal., 227 (2004) 384-397.

[24] M. Schwidder, M.S. Kumar, K. Klementiev, M.M. Pohl, A. Brückner, W. Grünert, J. Catal., 231 (2005) 314-330.

[25] D. Macina, Z. Piwowarska, K. Góra-Marek, K. Tarach, M. Rutkowska, V. Girman, A. Błachowski, L. Chmielarz, Mater. Res. Bull., 78 (2016) 72-82.

[26] D. Macina, A. Opioła, M. Rutkowska, S. Basąg, Z. Piwowarska, M. Michalik, L. Chmielarz, Mater. Chem. Phys., 187 (2017) 60-71.

[27] N. Maes, E.F. Vansant, Micropor. Mesopor. Mater., 4 (1995) 43-51.

[28] P. Forzatti, Appl. Catal. A, 222 (2001) 221-236.

[29] G. Busca, L. Lietti, G. Ramis, F. Berti, Appl. Catal. B, 18 (1998) 1-36.

[30] M.D. Amiridis, F. Puglisi, J.A. Dumesic, W.S. Millman, N.Y. Topsøe, J. Catal., 142 (1993) 572-584.

[31] P. Boroń, L. Chmielarz, J. Gurgul, K. Łątka, T. Shishido, J-M. Krafft, S. Dźwigaj, Appl. Catal. B, 138-139 (2013) 434-445. 
[32] P. Boroń, L. Chmielarz, J. Gurgul, K. Łątka, B. Gil, B. Marszałek, S. Dźwigaj, Micropor. Mesopor. Mat., 203 (2015) 73-85.

[33] G. Centi, S. Perathoner, Appl. Catal. A, 132 (1995) 179-259.

[34] O. Kröcher, M. Devadas, M. Elsener, A. Wokaun, N. Söger, M. Pfeifer, Y. Dembel, L. Mussmann, Appl. Catal. B, 66 (2006) 208-216.

[35] S. Brandenberger, O. Kröcher, A. Tissler, R. Althoff, Appl. Catal. B, 95 (2010) 348-357.

[36] P. Ciambelli, P. Corbo, M.C. Gaudino, F. Migliardini, D. Sannino, Top. Catal., 16, 1 (2001) 413-417.

[37] I. Ellmers, R. Pérez Vélez, U. Bentrup, W. Schwieger, A. Brückner, W. Grünert, Catal. Today, 258 (2015) 337-346

[38] J. Rouquerol, P. Llewellyn, F. Rouquerol, Stud. Surf. Sci. Catal., 160 (2007) 49-56.

[39] M. Thommes, K. Kaneko, A.V. Neimark, J.P. Olivier, F. Rodriguez-Reinoso, J. Rouquerol, K.S.W. Sing, Pure Appl. Chem., 87(9-10) (2015) 1051-1069

[40] M. Rutkowska, L. Chmielarz, M. Jabłońska, C. J. Van Oers, P. Cool, J. Porous Mater., 21 (2014) 91-98.

[41] M. Rutkowska, D. Macina, N. Mirocha-Kubień, Z. Piwowarska, L. Chmielarz, Appl. Catal. B, 174 (2015) 336-343.

[42] K. Sadowska, A. Wach, Z. Olejniczak, P. Kuśtrowski, J. Datka, Micropor. Mesopor. Mater., 167 (2013) 82-88.

[43] B. Gil, Ł. Mokrzycki, B. Sulikowski, Z. Olejniczak, S. Walas, Catal. Today, 152 (2010) 24-32.

[44] P. Sazama, B. Wichterlova, J. Dedecek, Z. Tvaruzkova, Z. Musilova, L. Palumbo, S. Sklenak, O. Gonsiorova, Micropor. Mesopor. Mater., 143 (2011) 87-96.

[45] P. Boroń, L. Chmielarz, J. Gurgul, K. Łątka, B. Gil, J-M. Krafft, S. Dźwigaj, Catal. Today, 235 (214) 210-225. 
[46] A. Wang, Y. Wang, E.D. Walter, R.K. Kukkadapu, Y. Guo, G. Lu, R.S. Weber, Y. Wang, C.H.F. Peden, F. Gao, J. Catal., 358 (2018) 199-210.

[47] Y. Xia, W. Zhan, Y. Guo, Y. Guo, G. Lu, Chinese J. Catal, 37 (2016) 2069-2078. 